\title{
GASTROINTESTINAL WATER AND ELECTROLYTES. I. THE EQUILIBRATION OF RADIOSODIUM IN GASTROINTESTINAL CONTENTS AND THE PROPORTION OF EXCHANGEABLE SODIUM $\left(\mathrm{Na}_{e}\right)$ IN THE GASTROINTESTINAL TRACT ${ }^{1}$
}

\author{
By I. S. EDELMAN 2 AND N. J. SWEET \\ (From the Department of Medicine, University of California School of Medicine, and the San \\ Francisco Hospital, San Francisco, Calif.)
}

(Submitted for publication September 14, 1955; accepted December 19, 1955)

The concept of the partition of body water and electrolytes into two anatomical entities, extracellular and intracellular fluid, is well established. This is based on their fundamental differences in electrolyte structure (1). More refined definitions of water and electrolyte anatomy have become possible by the application of tracer dilution methods to in vivo estimation of body water and electrolyte content $(2,3)$. Thus, ideas on the organization of extracellular fluid have undergone distinct evolution in recent years. It has been pointed out that the equilibration properties of sodium in bone and of inulin and thiosulfate in dense connective tissue distinguishes the extracellular phase of these tissues from free interstitial fluid $(4,5)$. The proposal has also been made that the term transcellular fluid be applied to those extracellular fluids which are not in simple diffusion equilibrium with plasma and are probably formed as a result of active cellular transport mechanisms (3). This would include fluid in the gastrointestinal tract, joint spaces, synovial sacs, cerebrospinal canal, anterior chamber of the eye, glandular ducts and acini, and in the renal tubules. The physiological significance of transcellular fluids will depend, in part, on the volume of these fluids and the extent of exchangeability of their individual components.

This and the three articles to follow (6-8) will report the results of studies on the magnitude of intraluminal gastrointestinal water and electrolytes in rabbits and humans and on the equilibration of

1 This work was carried out under grants from the American Heart Association, the United States Public Health Service (Grant No. H-1441), the Fleischmann Foundation, the San Francisco Heart Association, the Paul and Susan Gardiner Fund and the McKee Fund assigned by the Medical Research Committee of the University of California School of Medicine, San Francisco.

2 Established Investigator of the American Heart Association. gut water and electrolytes with body water and electrolytes, using tracer indicators, in rabbits. These studies were undertaken because a) the gastrointestinal contents probably contribute considerably to the volume of transcellular fluid, and b) it has been shown that there is rapid bi-directional transport of water and electrolytes between blood and the intestinal lumen (9). In some commonly used laboratory animals, such as the rabbit and guinea pig, intraluminal gastrointestinal water content estimated by desiccation methods constituted a major subdivision of body water (10).

This communication presents observations on a) the amount of intraluminal gastrointestinal sodium relative to total exchangeable sodium $\left(\mathrm{Na}_{\mathrm{e}}\right)$ and the extent of radiosodium exchange equilibrium in gastrointestinal contents in rabbits and b) the amount of intraluminal gastrointestinal sodium in human cadavers.

\section{METHODS}

\section{A. Rabbits}

Forty adult albino rabbits were studied in pairs consisting of a male and a non-gravid female. The animals were allowed to consume pellets and water ad libitum until the time of injection, or else water was allowed ad libitum but food was withheld for a variable period of time before sacrifice. The average sodium intake prior to fasting was $15 \mathrm{mEq}$. per day. Figures 1 and 2 depict the periods of fasting up to the time of sacrifice.

All animals were injected intraperitoneally with 100 to 150 microcuries of $\mathrm{Na}^{21} \mathrm{Cl}^{3}$ from calibrated syringes. The injected solution was made isotonic with $\mathrm{NaCl}$, sterilized and neutralized to $\mathrm{pH}$ 7.0. Isotopic purity was evaluated by prolonged observations of the rates of decay on aliquots taken from each shipment. At the time of radioassay there was less than 8 per cent contamination

3 Prepared by deuteron bombardment of $\mathrm{Na}^{*} \mathrm{Cl}$ in the 60 inch cyclotron in the Crocker Radiation Laboratory, University of California, Berkeley. 


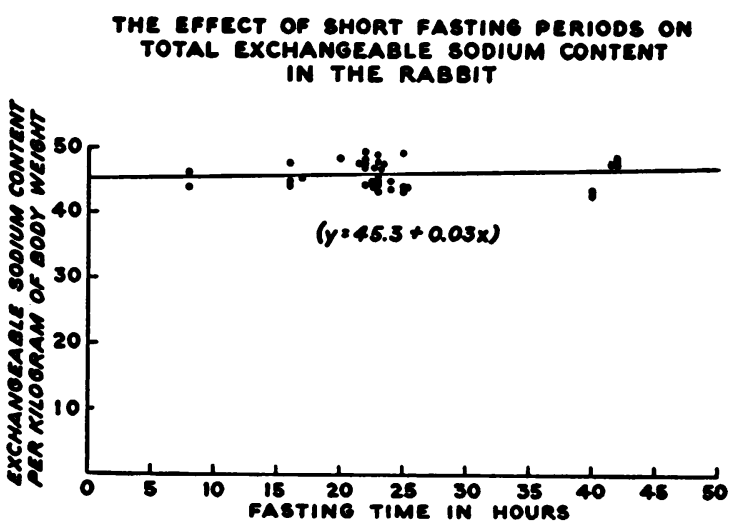

Fig. 1. The Effect of Fasting Periods of 8 to 44 Hours on the Total Exchangeable Sodium Content IN RABBITS

Water was allowed ad libitum. The line drawn through the experimental values was determined by the method of least squares.

with $P^{n}$. The scintillation counting technique employed, however, detects virtually none of this contaminant since $\mathbf{P}^{*}$ electrons are absorbed by the shield in this system. Urine and stool passed during the period of isotope equilibration were collected in metabolism cages. The rabbits were anesthetized with $2 \mathrm{ml}$. of 2 per cent Nembutale administered into a dorsal ear vein 20 to 26 hours after injection of radiosodium and then were weighed to the nearest gram. Cardiac blood was drawn by puncture through the intact chest wall. The abdominal cavity was opened, and all bladder urine was aspirated and pooled with the cage urine. Double ligatures were placed at the cardia of the stomach, pylorus, ileocecal valve and the mid-transverse colon. The intact serosal surfaces were washed with distilled water and carefully dried to prevent contamination of the pans with blood. The rubber gloves worn by the experimenters were carefully washed off with distilled water. Each segment of the gastrointestinal tract was removed separately, opened along the long axis, and the contents were carefully emptied into distilled water-rinsed containers. The mucosal surfaces were stripped as gently as possible, but a thin layer of mucus invariably clung to the mucosal surface. Absolute recovery of gastrointestinal contents was not attempted in order to avoid bleeding or epithelial damage. The evacuated contents were transferred quantitatively to graduated cylinders with multiple rinses using more than $100 \mathrm{ml}$. of distilled water in every instance. The volumes were recorded, and aliquots were filtered through glass wool. Aliquots of serum, gastrointestinal contents, urine and stool were taken for radioactive assay and chemical analysis.

One-ml. aliquots of serum, gastrointestinal contents and urine were plated in triplicate on filter paper, dried under an infra-red lamp and covered with parafilm. Three separate dilutions of the injected solution were each plated in triplicate and processed as above. Radioactivity assays were carried out with an aluminum-covered end- window, thallium-activated sodium iodide scintillation counter and autoscaler. Preliminary observations revealed that self-absorption loss was not encountered up to twice the quantity of solids present in the experimental samples and that coincidence loss was not detected up to five times the counting rates of the experimental samples. All samples, however, were corrected for background and radioactive decay $\left(T_{1 / 2}=15.04\right.$ hours [11]). A minimum of 5,000 counts were collected on each planchet.

Triplicate sodium analyses were made from duplicate dilutions on aliquots of serum, gastrointestinal contents, urine and stool with a lithium internal standard flame photometer (Baird Associates- Na II filter). Since random samples of gastrointestinal contents contained less than $12 \mathrm{mEq}$. per liter of calcium, a correction for the contribution of calcium emission to sodium assays was unnecessary.

\section{B. Human subjects}

Thirteen human subjects were studied at the time of postmortem examination. The gross and microscopic postmortem findings, as well as the age, sex, body weight and height of each subject, were recorded. Patients with demonstrable edema or organic gastrointestinal disease were eliminated from the study.

Double ties were placed at the cardio-esophageal junction, the pylorus of the stomach, the ileocecal valve, and just distal to the hepatic flexure of the transverse colon. The tract was separated into segments by cutting between ties and removed from the peritoneal cavity. The serosal surfaces were trimmed, washed with distilled water, carefully dried, and each segment of the tract weighed on a torsion balance to within 1.0 gram. Each segment of the tract was opened along its long axis. The mucosal surfaces were stripped with a gloved finger, and the contents transferred to distilled water-cleaned

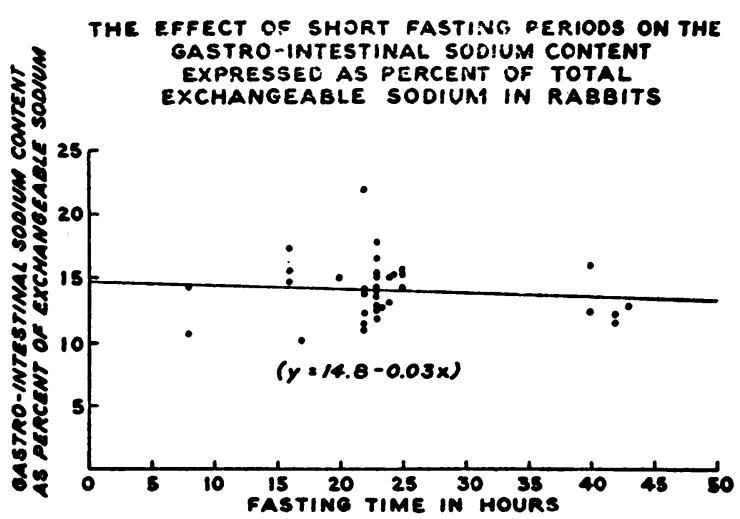

Fig. 2. The Effect of Fasting Intervals on the Gastrointestinal Sodiuy Content of Rabbits Relative to the Total Exchangeable Sodrum Content

Water was allowed ad libitum. The line drawn through the experimental values was determined by the method of least squares. 
pans, using multiple distilled water rinses. The wall of each portion of the tract was carefully dried and reweighed. A thin layer of mucus invariably clung to the mucosal surfaces at the end of these manipulations. The gastrointestinal contents were homogenized, the total volume recorded using graduated cylinders, and aliquots were taken for estimation of total solids, chloride, sodium and potassium.

Triplicate sodium analyses were made from duplicate dilutions of the separate gastrointestinal contents with a lithium internal standard flame photometer (Baird Associates- $\mathrm{Na}$ II filter).

\section{CALCULATIONS}

\section{A. Rabbits}

The total exchangeable sodium content $\left(\mathrm{Na}_{\odot}\right)$ was calculated from the dilution formula (2):

where:

$$
\mathrm{Na}_{0}=\frac{\mathrm{Na}_{i}{ }^{24}-\mathrm{Na}_{0}{ }^{24}}{\mathrm{Na}_{8}{ }^{24} / \mathrm{Na}_{8}{ }^{23}}
$$

$\mathrm{Na}_{i}{ }^{24}=$ injected radiosodium in counts per minute.

$\mathrm{Na}_{0}{ }^{24}=$ radiosodium excreted in the urine (bladder plus cage urine) to time of equilibrium blood sample.

$\mathrm{Na}_{8}{ }^{24} / \mathrm{Na}_{\mathrm{s}}{ }^{\mathrm{n}}=$ serum specific activity at equilibrium of distribution in counts per $\mathrm{mEq}$.

In these studies the equilibrium samples were obtained 20 to 26 hours after administration of the radiosodium solution. Urinary loss of radiosodium during this period averaged 6.6 per cent of the injected amount, with a range of 2.2 to 10.7 per cent.

The degree of ionic exchange of intraluminal sodium with serum sodium was evaluated by relating gastrointestinal specific activities to the serum specific activities. The fraction of the tissue element, in this case intraluminal sodium, exchanged with serum element is given by the formula :

$$
\text { Specific activity ratio (S.A.R.) }=\text { F.E. }=\frac{(\text { S.A. })_{t}}{(\text { S.A. })_{\mathrm{t}}}
$$
where:

F.E. = fraction exchanged.

(S.A.) $)_{t}=\mathrm{Na}_{t}{ }^{24} / \mathrm{Na}_{t}{ }^{23}=$ tissue specific activity at equilibrium of distribution in counts per $\mathrm{mEq}$.

(S.A.) $)_{\mathrm{s}}=\mathrm{Na}_{\mathrm{e}}{ }^{24} / \mathrm{Na}_{\mathrm{e}}{ }^{23}=$ serum specific activity at equilibrium of distribution in counts per $\mathrm{mEq}$.

The derivation of this formula requires that the serum specific activity be constant or almost constant at the time of tissue sampling (4). Although equating the specific activity ratio $\frac{\text { (S.A.) }}{\text { (S.A.). }}$ to the fraction exchanged is not rigorously precise, it is sufficiently accurate for the purposes of this study.

\section{B. Human subjects}

The intraluminal gastrointestinal sodium content has been expressed as an absolute quantity ( $\mathrm{mEq}$.), as the amount per unit of body weight (mEq. per $\mathrm{kgm}$.) and as a per cent of the "predicted" total exchangeable sodium content ( $c f$. Table VI). To reduce the data to a fraction of the labile pool of body sodium it was necessary to predict the $\mathrm{Na}_{0}$ in each subject. For this purpose we used the previously published normal standards (12), rather than attempting to take into account deviations induced by a particular disease state. The mean value listed in these tables was applied to each patient according to sex and age, using the body weight as the reference unit. In studies on patients with a wide variety of disease states, the $\mathrm{Na}_{\text {。 }}$ was invariably found to be less than twice the expected normal values in edema-free subjects (13). It seems most likely, therefore, that the gastrointestinal sodium content expressed as per cent of the $\mathrm{Na}_{0}$ is accurate, at least to within a factor of 2 as a postmortem estimate. The absolute error resulting from agonal or postmortem migration of sodium across the gastrointestinal mucosa is unknown. The method employed has the advantage of eliminating the possibility of weighting the data by arbitrary selection of a predicted $\mathrm{Na}_{0}$ value.

\section{RESULTS}

\section{A. Rabbits}

To evaluate the possibility of sex-linked differences in either total exchangeable sodium content or the relative amount of intraluminal gastrointestinal sodium content, the rabbits were studied in pairs consisting of a male and a non-gravid female. The pairs of animals were subjected to identical fasting periods. Table I details comparisons of the $\mathrm{Na}_{e}, \mathrm{Na}_{\mathrm{e}}$ per $\mathrm{kgm}$. of body weight and the "total" gastrointestinal sodium between male and female rabbits matched for age and body weight. "Total" gastrointestinal sodium refers to the intraluminal sodium content of the gastroin-

TABLE I

The exchangeable sodium ( $\mathrm{Na}$ ) and gastrointestinal sodium

\begin{tabular}{|c|c|c|c|c|}
\hline & Male & Female & $\mathbf{t}$ & p \\
\hline Number & 16 & 16 & & \\
\hline $\begin{array}{c}\text { Body weight in } \\
\text { kgm. } \pm \text { s.d.* }\end{array}$ & $2.14 \pm 0.20$ & $2.09 \pm 0.12$ & 0.83 & $>0.4$ \\
\hline $\begin{array}{l}\mathrm{Na}_{\text {o in }} \\
\text { mEq. } \pm \text { s.d. }\end{array}$ & $96.5 \pm 6.5$ & $96.5 \pm 7.3$ & 0 & 1.0 \\
\hline $\begin{array}{l}\mathrm{Na}_{\text {e }} / \text { body weight in } \\
\text { mEq./kgm. } \pm \text { s.d. }\end{array}$ & $45.3 \pm 2.3$ & $46.2 \pm 2.3$ & 1.07 & $>0.2$ \\
\hline $\begin{array}{l}\text { "Total" G-I so- } \\
\text { dium } \nmid \text { as \% of } \\
\text { Na. } \pm \text { s.d. }\end{array}$ & $14.0 \pm 2.1$ & $14.3 \pm 2.4$ & 0.37 & $>0.7$ \\
\hline
\end{tabular}
content of male versus female rabbits 
testinal tract from the cardia of the stomach to the mid-transverse colon. The $p$ values for either body sodium content or the proportion of body sodium within the gastrointestinal tract do not achieve statistical significance. Because of these findings subsequent tabulations were made without regard to the sex of the individual animals.

Since the quantity of sodium in the gastrointestinal contents could be a function of food intake either by direct addition or by stimulation of gastrointestinal secretions, the effect of short fasting periods on the $\mathrm{Na}_{e}$ and "total" gastrointestinal sodium expressed as per cent of $\mathrm{Na}_{e}$ was investigated; the results are depicted in Figures 1 and 2. The periods of fasting varied from 8 to 43 hours. Within this interval as judged by the slope " $\lambda$," there is an insignificant effect on $\mathrm{Na}_{e}(\lambda=+$ 0.03 per hour) and on the gastrointestinal fluid sodium content ( $\lambda=-0.03$ per hour). These data indicate that short fasting periods insured basal gut fluid sodium contents without depletion of body sodium or shifts of sodium from the lumen of the gastrointestinal tract to the carcass.

Table II enumerates two fundamental parameters of body sodium anatomy, namely, the serum sodium concentration and the exchangeable sodium content. Serum sodium concentrations averaged $145 \pm 4 \mathrm{mEq}$. per liter, essentially the same as in humans. Exchangeable sodium content averaged $46.0 \pm 2.0 \mathrm{mEq}$. per $\mathrm{kgm}$. of body weight, whereas in humans the $\mathrm{Na}_{\mathrm{e}}$ averages $41.0 \pm 5 \mathrm{mEq}$. per kgm. (12).

Exchange equilibrium between gastrointestinal sodium and body sodium was evaluated by expressing the specific activity of gut fluid as a fraction of the serum specific activity (cf. Table III). The values of $0.95 \pm 0.128$ for stomach, $0.97 \pm 0.045$ for small intestine, $0.99 \pm 0.049$ for
TABLE II

The exchangeable sodium $\left(N a_{0}\right)$ content in the rabbit *

\begin{tabular}{|c|c|c|c|c|}
\hline & \multirow{2}{*}{$\begin{array}{c}\text { Body } \\
\text { weight } \\
\text { kgm. }\end{array}$} & \multirow{2}{*}{$\begin{array}{c}\text { Serum } \\
\mathrm{Na} \\
m E q . / L\end{array}$} & \multicolumn{2}{|c|}{$\begin{array}{c}\text { Exchangeable } \mathrm{Na} \\
m E q . /\end{array}$} \\
\hline & & & $m E q$. & kgm. \\
\hline Number & 35 & 35 & \multicolumn{2}{|c|}{35} \\
\hline Mean & 2.12 & 145 & 97.4 & 46.0 \\
\hline s.d. & \pm 0.21 & \pm 4 & \pm 7.1 & \pm 2.0 \\
\hline $\begin{array}{l}\text { Coefficient of } \\
\text { variation }\end{array}$ & $10.0 \%$ & $2.8 \%$ & $7.3 \%$ & 4.3 \\
\hline
\end{tabular}

* Fasting period varied from 8 to 43 hours prior to sacrifice.

cecum and transverse colon, and $0.99 \pm 0.036$ for the "total" gastrointestinal tract indicate that all of the gut sodium is freely exchanged with extracellular sodium. The small differences from unity were evaluated by the formula :

$$
\mathrm{t}=\frac{1.00-\overline{\mathrm{x}}}{\text { s.e. }}
$$

where:

$$
\begin{aligned}
\overline{\mathbf{x}} & =\text { mean value } \\
\text { s.e. } & =\text { standard error }
\end{aligned}
$$

The $p$ value for small intestine sodium exchange is $<0.02$ and does achieve statistical significance. However, the quantity of sodium involved ( 3 per cent) is negligible.

The magnitude of intraluminal gastrointestinal sodium content is summarized in Table IV. "Total" gastrointestinal sodium is $14.2 \pm 2.4$ per cent of the $\mathrm{Na}_{e}$; with the smallest fraction in the stomach, $0.9 \pm 0.4$ per cent of the $\mathrm{Na}_{e}$, an intermediate amount in the small intestine, $3.2 \pm 1.2$ per cent of the $\mathrm{Na}_{\mathrm{e}}$, and the major portion in the cecum and proximal transverse colon, 10.2 \pm 2.1 per cent of the $\mathrm{Na}_{\mathrm{e}}$. The proximal segment of the large bowel, therefore, contains 72 per cent of the total gastrointestinal sodium in the normal rabbit.

\begin{tabular}{|c|c|c|c|c|c|c|}
\hline & \multirow[b]{2}{*}{ Number } & \multirow{2}{*}{$\begin{array}{l}\text { Fasting } \\
\text { period } \\
\text { hours }\end{array}$} & \multicolumn{4}{|c|}{ Specific activity ratiof } \\
\hline & & & Mean & 8.d. & $\mathbf{t}$ & p \\
\hline $\begin{array}{l}\text { Stomach } \\
\text { Small intestine }\end{array}$ & $\begin{array}{l}17 \\
17\end{array}$ & $\begin{array}{l}20-24 \\
20-24\end{array}$ & $\begin{array}{l}0.95 \\
0.97\end{array}$ & $\begin{array}{l} \pm 0.128 \\
\pm 0.045\end{array}$ & $\begin{array}{l}1.61 \\
2.74\end{array}$ & $\begin{array}{l}>0.1 \\
>0.01 \\
<0.02\end{array}$ \\
\hline $\begin{array}{l}\text { Cecum and transverse colon } \\
\text { "Total" G-I }\end{array}$ & 17 & $\begin{array}{r}20-24 \\
8-43\end{array}$ & $\begin{array}{l}0.99 \\
0.99\end{array}$ & $\begin{array}{l} \pm 0.049 \\
\pm 0.036\end{array}$ & $\begin{array}{l}0.84 \\
1.15\end{array}$ & $>0.4$ \\
\hline
\end{tabular}

TABLE III

The equilibration of $\mathrm{Na}^{24}$ with intraluminal gastrointestinal sodium in the rabbit*

* $\mathrm{Na}^{24} \mathrm{Cl}$ was injected intraperitoneally 20 to 25 hours prior to sacrifice.

$\dagger$ This ratio was obtained by dividing the specific activity of the gastrointestinal contents by the specific activity of the serum. 
TABLE IV

The intraluminal gastrointestinal sodium content in the rabbit

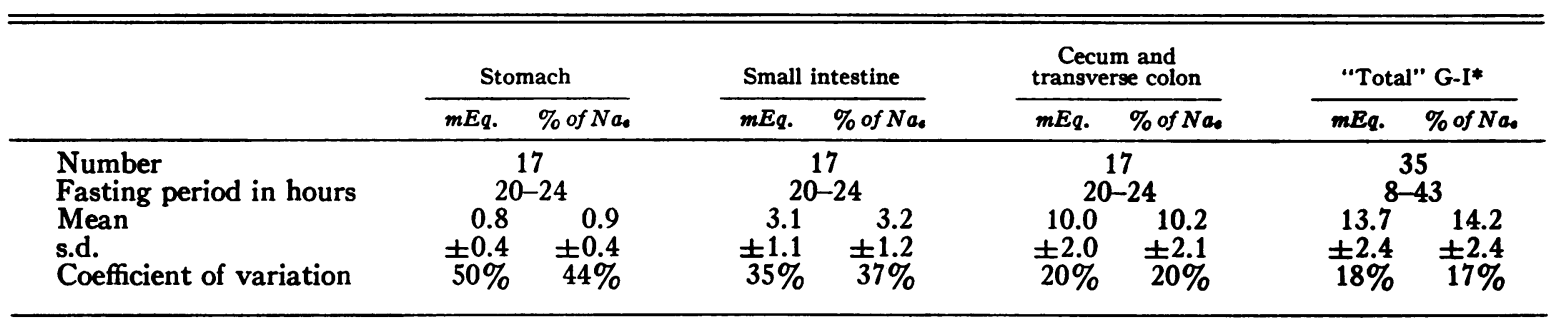

* "Total" G-I sodium refers to the intraluminal sodium content of the gastrointestinal tract from the cardia of the stomach to the mid-transverse colon.

The impressive amount of sodium in the cecum and proximal transverse colon raises the possibility of fairly large rates of sodium loss in the stool. This question was examined by measuring the intraluminal sodium content of the descending colon and rectum and by quantitative 24-hour stool collections during short fasting periods (16 to 41 hours). The results are listed in Table V. The distal large bowel had a mean sodium content of 1.9 per cent of the "total" gastrointestinal sodium content, and the rate of stool sodium excretion averaged $0.40 \mathrm{mEq}$. per day, which is equivalent to 2.9 per cent of the "total" gastrointestinal sodium or 0.41 per cent of the $\mathrm{Na}_{\mathrm{e}}$. The cecal mechanism for sodium conservation is apparently quite efficient.

\section{B. Humans}

The results obtained on postmortem examination are listed in Table VI. The interval from the time of death to the time of collection of gastrointestinal contents varied from 6 to 22 hours. Perusal of the data indicates that there is no gross relation between the quantity of gastrointestinal

TABLE V

The sodium content of the distal colon and the rate of stool sodium excretion in the rabbit

\begin{tabular}{|c|c|c|}
\hline & $\begin{array}{l}\text { Deacending colon } \\
\text { and rectum }\end{array}$ & $\begin{array}{l}\text { Stool sodium per } \\
24 \text { hours }\end{array}$ \\
\hline & $\begin{array}{l}\text { Tolal } \\
\text { mEq. }\end{array}$ & $\begin{array}{l}\text { Total \%of "Tolal" } \\
\text { mEq. G-I sodium" }\end{array}$ \\
\hline $\begin{array}{l}\text { Number } \\
\text { Fasting period } \\
\text { in hours }\end{array}$ & $\begin{array}{c}8 \\
22-41\end{array}$ & $\begin{array}{c}16 \\
16-41\end{array}$ \\
\hline $\begin{array}{l}\text { Mean } \\
\text { Range }\end{array}$ & $\begin{array}{cc}0.28 & 1.9 \\
0.06-0.56 & 0.6-4.1\end{array}$ & $\begin{array}{cc}0.40 & 2.6 \\
0-1.47 & 0-8.2\end{array}$ \\
\hline
\end{tabular}

* "Total" G-I sodium refers to the intraluminal sodium content of the gastrointestinal tract from the cardia of the stomach to the mid-transverse colon. sodium and the interval between death and postmortem examination. The smallest quantity of gastrointestinal sodium (15.4 mEq.) was found in a patient with an 11-hour postmortem interval; the largest amount ( $70.5 \mathrm{mEq}$.) was found in a patient with a 12-hour postmortem interval. This series consisted of 13 patients, 8 males and 5 females, varying in age from 50 to 77 years. The clinical and pathological features of these cases are summarized in the appendix.

To express the intraluminal gastrointestinal sodium content in terms of the total labile pool of body sodium, a predicted $\mathrm{Na}_{\mathbf{e}}$ was calculated for each case from previously published normal values (12), taking into account the patient's age, sex and body weight. Mean "total" gastrointestinal sodium was $0.54 \mathrm{mEq}$. per $\mathrm{kgm}$. of body weight, or 1.6 per cent of the predicted $\mathrm{Na}_{\mathrm{e}}$. Stomach and proximal large bowel sodium contents almost equaled each other, averaging 0.18 $\mathrm{mEq}$. per $\mathrm{kgm}$. of body weight, or 0.45 per cent of the predicted $\mathrm{Na}_{e}$, and $0.14 \mathrm{mEq}$. per $\mathrm{kgm}$. of body weight, or 0.36 per cent of the predicted $\mathrm{Na}_{e}$, respectively. Small bowel contents contained the largest fraction of gut sodium with a mean value of $0.30 \mathrm{mEq}$. per $\mathrm{kgm}$. of body weight or 0.74 per cent of the predicted $\mathrm{Na}_{\mathrm{e}}$.

\section{DISCUSSION}

Sodium is universally present, usually in high concentrations, in body secretions. In humans the lowest concentrations of sodium tend to occur in stomach and cecal aspirates, averaging 60.4 and $52.5 \mathrm{mEq}$. per liter, respectively, while the highest concentrations occur in biliary and pancreatic secretions, averaging 148.9 and $141.1 \mathrm{mEq}$. per liter, respectively (14). Nevertheless, sodium in the gastrointestinal tract has been ignored 


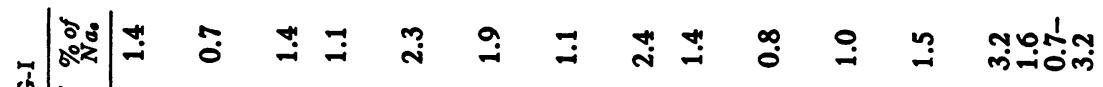

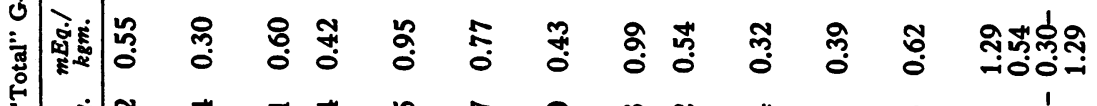
|

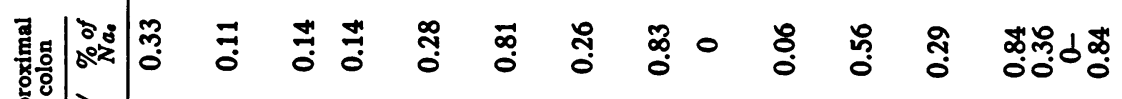

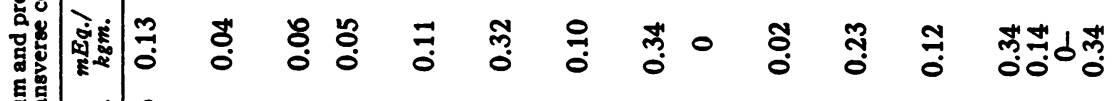

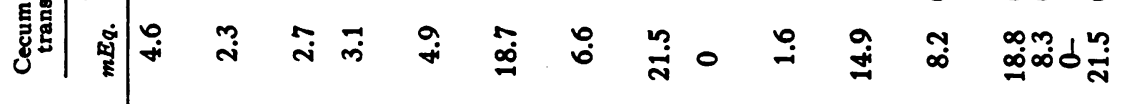

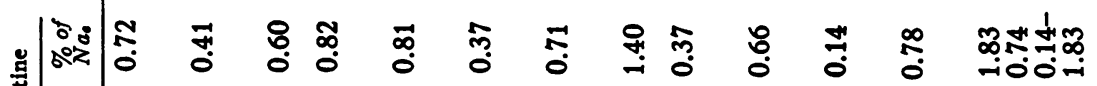
焉 步

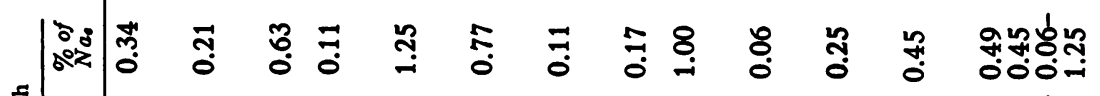
蹗 มี่

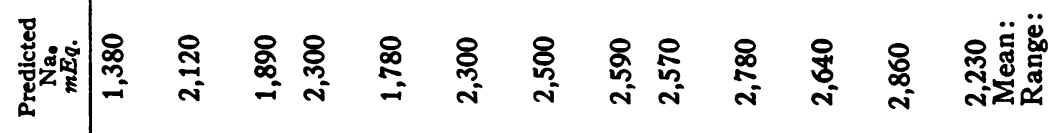

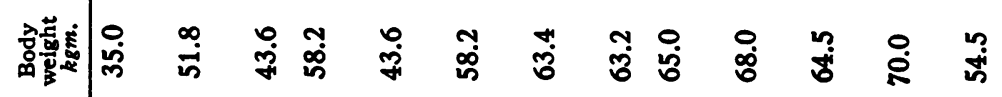

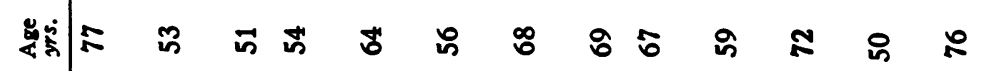
คำด

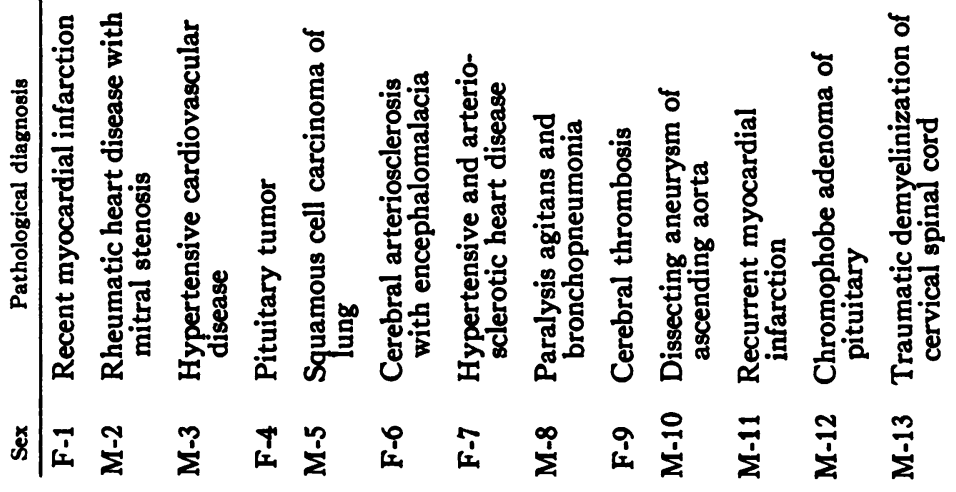


in past considerations of body water anatomy. This is in spite of the fact that in many species the volume of intraluminal gastrointestinal fluid is considerable $(10,15)$.

The justification for separate identification of gut lumen contents rests firmly on both anatomical and physiological grounds. Anatomically, gastrointestinal sodium is clearly extracellular and falls in the same general category as plasma and interstitial fluid. However, the similarity ends there. Visscher and his co-workers have shown that the intraluminal gut-plasma concentration ratios for sodium, chloride and hydrogen ions may exceed 100 ; that water may enter the intestinal phase against a concentration gradient; that sodium may leave the intestinal phase against a concentration gradient; that the total flux of sodium ion across the intestinal mucosa is higher at the oral end; and that the flux of sodium out of the intestinal lumen relative to inward flux is greatest at the aboral end of bowel $(9,16-18)$. These findings indicate that exchange across the gastrointestinal mucosa probably involves active transport mechanisms and is not entirely a function of simple diffusion or pressure gradients. The decreased transport of sodium from ileal loop to blood during adrenal cortical insufficiency (19) and the decreased gastrointestinal sodium content in ACTHtreated, fasted, nephrectomized rats (20) support this conclusion, since hormonal influences on active transport mechanisms are well known.

The gastrointestinal specific activity ratios of $0.95,0.97,0.99$ and 0.99 for stomach, small intestine, proximal large bowel and "total" gastrointestinal contents, respectively, confirms the complete exchangeability of gastrointestinal sodium. This phase of sodium is, therefore, an integral part of the body pool of labile sodium. The lability of gastrointestinal sodium is undoubtedly not unique for rabbits, since it has been shown that there is rapid blood-to-gut (both small and large bowel) lumen transport of sodium in dogs and blood to gastric juice transport of sodium in humans $(18,21)$. These data also indicate that estimates of total exchangeable sodium by radiosodium dilution include intraluminal gastrointestinal sodium, as is the case in other transcellular fluids, such as cerebrospinal fluid and pancreatic juice (21-23). Isotopic exchange, however, does not indicate the nature of the mechanism of gastro- intestinal transport. It establishes that there is blood-to-gut transport but does not distinguish among passive diffusion, exchange diffusion, electroosmosis or active transport dependent on metabolic energy.

The amount of intraluminal gastrointestinal sodium in the rabbit is substantial. It is of interest that in this species, 14.2 per cent of the $\mathrm{Na}_{e}$ is in the gut, and 72 per cent of this quantity or 10.2 per cent of the $\mathrm{Na}_{e}$ is in the cecum and proximal half of the transverse colon. The distal colon contains only 1.9 per cent of the "total" gastrointestinal sodium, and the stool excretion rates averaged 2.9 per cent of the "total" gastrointestinal sodium or 0.4 per cent of the $\mathrm{Na}_{\mathbf{e}}$ (cf. Table V). Visscher, Varco, Carr, Dean, and Erickson (18) found that sodium flux out of the colon exceeded sodium flux into the colon considerably in dogs. Judged by these findings the proximal and midcolon conserve sodium quite efficiently. The human gastrointestinal tract may contain much less sodium than the rabbit's, since postmortem analyses gave values averaging 1.6 per cent of the predicted $\mathrm{Na}_{e}$, and its distribution differs in that the small intestine contains 46 per cent of this quantity, with the remainder about equally distributed between the stomach and proximal colon ( $c f$. Table VI). We cannot assume, of course, that these values apply to the living normal subject. Differences in gastrointestinal sodium content between rabbit and postmortem man may have significance, however, in view of similar differences in intraluminal gastrointestinal water contents between various species noted by Cizek (10). The collection of gastrointestinal fluid at postmortem after catastrophic illness, needless to say, does not afford a sound basis for estimating normal values. The justification for this examination rests in the fact that animal data cannot be transposed to humans. Indeed, premortem shifts of sodium under hormonal or other physiological influences may account for the low intraluminal sodium contents found in the human subjects.

The total exchangeable sodium of normal adult humans averages $41.0 \mathrm{mEq}$. per $\mathrm{kgm}$. of body weight $(12,21,22)$. The young adult rabbit has a mean $\mathrm{Na}_{\mathrm{e}}$ of $46.0 \mathrm{mEq}$. per $\mathrm{kgm}$. of body weight, which is significantly greater than the human value (cf. Table II). This difference may be due, at least in part, to greater intraluminal gastroin- 
testinal sodium content in the rabbit. "Total" gut sodium averages 14.2 per cent of the $\mathrm{Na}_{e}$, which is equivalent to $6.5 \mathrm{mEq}$. per $\mathrm{kgm}$. of body weight ( $c f$. Table IV). In the human subjects studied postmortem, "total" gastrointestinal sodium averaged $0.54 \mathrm{mEq}$. per $\mathrm{kgm}$. of body weight. The additional $6.0 \mathrm{mEq}$. of sodium per $\mathrm{kgm}$. of body weight in the rabbit gut would, therefore, neatly match the difference in the $\mathrm{Na}_{e}$ of $5.0 \mathrm{mEq}$. per $\mathrm{kgm}$. of body weight between the two species. Since postmortem studies after catastrophic illness are obviously not adequate for judgment of normal values, there is a need for further studies in human subjects, particularly in previously well individuals soon after sudden accidental death.

Kruhøffer (24) estimated the interstitial fluidplasma volume in rabbits by inulin volume of dilution to be slightly less than 20 per cent of the body weight. This volume would contain approximately $60 \mathrm{mEq}$. of sodium. If there is a shift of sodium from the gastrointestinal tract to the interstitial-plasma compartment in response to metabolic need, gut sodium could replace up to 20 per cent of the interstitial-plasma sodium in rabbits. During short fasting periods, however, we found little or no redistribution of sodium between gut and carcass ( $c f$. Figure 2). In humans, shifts into this compartment might produce significant internal loss of sodium from the interstitial-plasma compartment. The finding of decreased fecal extraction of sodium with cation exchange resins in patients with edema suggests that disease states may alter sodium exchange or induce shifts of sodium across intestinal mucosa (25).

The equilibration of radiosodium with transcellular sodium is of significance in the interpretation of body sodium anatomy based on simultaneous dilution methods using inulin and sucrose. These saccharides apparently do not penetrate gastric juice, bile or cerebrospinal fluid $(24,26-28)$. The estimation of intracellular sodium by subtraction of the sodium in the inulin or sucrose volume of dilution from the total exchangeable sodium would therefore be in error in proportion to the quantity of transcellular sodium in the animals under study.

\section{SUMMARY}

Intraluminal gastrointestinal sodium content was measured in rabbits and in humans studied post- mortem. In the former, gut sodium was referred to $\mathrm{Na}_{\mathrm{e}}$ estimated with $\mathrm{Na}^{24}$, while in the latter, gut sodium was referred to predicted $\mathrm{Na}_{\mathbf{e}}$ values.

Total exchangeable sodium averaged $46.0 \pm$ $2.0 \mathrm{mEq}$. per kgm. of body weight in rabbits. Of this, $14.2 \pm 2.4$ per cent was found to be in the gastrointestinal tract, with $0.9 \pm 0.4$ per cent in the stomach, $3.2 \pm 1.2$ per cent in the small intestine, and $10.2 \pm 2.1$ per cent in the proximal half of the large intestine. Radiosodium exchange equilibrium was virtually complete 24 hours after injection at all levels of the gastrointestinal tract. Fasting periods of 8 to 43 hours did not affect the quantity or distribution of gastrointestinal sodium to any appreciable extent. No significant difference in either $\mathrm{Na}_{\mathrm{e}}$ or the quantity of intraluminal gastrointestinal sodium was found between male and female rabbits.

Human subjects at postmortem after a variety of diseases had relatively small amounts of intraluminal gastrointestinal sodium; the mean values were 1.6 per cent of the predicted $\mathrm{Na}_{e}$ in the "total" gastrointestinal tract, with 0.45 per cent in the stomach, 0.74 per cent in the small bowel and 0.36 per cent in the proximal portion of the large bowel. These data, however, cannot be taken as a reliable guide to the quantity of intraluminal sodium in living man.

The implications of these data are discussed in terms of the dynamics of sodium transport across the intestinal mucosa and the anatomy of body sodium.

\section{ACKNOWLEDGMENTS}

The authors wish to thank Drs. J. Nadell and F. Gotch for their assistance in carrying out these studies. Grateful acknowledgment is also made to Miss M. R. Halligan who did much of the technical work.

\section{APPENDIX}

\section{Summary of case histories}

F-1. Patient G. A., SFH 126096, female, aged 77 years. Patient expired 24 hours after admission.

Postmortem examination revealed: marked coronary atherosclerosis, myocardial fibrosis, recent infarct of the interventricular septum, $600 \mathrm{ml}$. of fluid in both pleural cavities, moderate pulmonary edema, calcification of the abdominal aorta and chronic cholecystitis with cholelithiasis.

$M$-2. Patient J. F., SFH 56451, male, aged 53 years. Patient expired in coma 11 days after admission. 
Postmortem examination revealed : mitral stenosis, congestive heart failure with passive congestion of lungs, liver, spleen and kidneys, mural thrombus of left auricle, multiple pulmonary emboli, multiple emboli to brain stem, saddle embolus at bifurcation of the aorta, chronic pyelonephritis and chronic cholecystitis with cholelithiasis.

M-3. Patient J. W., SFH 179284, aged 51 years. Admitted in coma, with a known history of hypertension. Patient expired 1 hour after admission.

Postmortem examination revealed: hypertrophy of both ventricles, marked arteriolar nephrosclerosis, pulmonary congestion, occlusion of the right vertebral artery with multiple cerebellar and pontine infarcts, and coronary artery atherosclerosis with focal myocardial fibrosis.

F-4. Patient B. N., SFH 1693, female, aged 54 years. Present admission was for diabetic acidosis and coma. Patient expired 19 days after admission.

Postmortem examination revealed: necrotic pituitary tumor, type undetermined, mild glomerulosclerosis, bilateral cataracts, generalized arteriosclerosis involving the heart, kidneys and peripheral arteries, and a bilateral bronchopneumonia.

$M$-5. Patient F. D., SFH 133435, male, aged 64 years. Patient died 38 days after admission.

Postmortem examination revealed: pulmonary squamous cell carcinoma of left lower lobe with metastases to mediastinal and abdominal lymph nodes, pericardium and adrenals, acute bilateral bronchopneumonia, and generalized arteriosclerosis involving the aorta, coronary and renal arteries.

F-6. Patient N. R., SFH 134788, female, aged 56 years. Patient expired in coma 5 days after admission.

Postmortem examination revealed: cerebral atherosclerosis with encephalomalacia of right cerebral hemisphere, coronary atherosclerosis, left ventricular hypertrophy, nephrosclerosis, pulmonary emphysema and bronchopneumonia, moderate bronchiectasis, mild mitral stenosis, mild passive congestion of the liver, moderate fibrosis of the thyroid gland and chronic cholecystitis with cholelithiasis.

F-7. Patient G. W., SFH N-132431, female, aged 68 years. Patient expired two months after admission, soon after the onset of severe chest pain.

Postmortem examination revealed: healing myocardial infarction of the posterior left ventricle, chronic passive congestion of the lungs, liver and spleen, nephrosclerosis and chronic cholecystitis with cholelithiasis.

M-8. Patient G. H., SFH 135018, male, aged 69 years. Patient expired 11 days after admission.

Postmortem examination revealed: severe coronary atherosclerosis with an area of healed myocardial infarction, bilateral bronchopneumonia, demyelinization and gliosis of the basal ganglia, arteriosclerosis involving the aorta, renal and cerebral vessels, and chronic cholecystitis with cholelithiasis.

F-9. Patient A. F., SFH 135355, female, aged 67 years. Patient expired 43 days after admission.

Postmortem examination revealed: generalized arteriosclerosis with cerebral thrombosis and infarction, con- genital atrophy of the right kidney, and marked bilateral pulmonary congestion.

M-10. Patient L. Y., SFH N-136139, male, aged 59 years. Patient expired five hours after admission.

Postmortem examination revealed: dissecting aneurysm of ascending aorta with hemopericardium, generalized arteriosclerosis and focal pulmonary fibrosis.

M-11. Patient I. P., SFH N-135687, male, aged 72 years. On the thirty-fourth hospital day patient developed severe pulmonary edema, became hypotensive and died a few hours later.

Postmortem examination revealed: coronary atherosclerosis with recent and old areas of myocardial infarction and a ventricular aneurysm, bilateral moderate nephrosclerosis, chronic passive congestion of the lungs, liver and spleen, and severe bilateral bronchopneumonia.

$M$-12. Patient A. D., SFH N-136536, male, aged 50 years. Patient expired on the sixth postoperative day following craniotomy for a pituitary tumor.

Postmortem examination revealed: cerebral infarction of left posterior hemisphere, a chromophobe adenoma of the pituitary and bilateral bronchopneumonia.

M-13. Patient A. T., SFH 17353, male, aged 76 years. Patient died suddenly 4 days after admission for posttraumatic quadriplegia.

Postmortem examination revealed: demyelinization of cervical spinal cord, generalized arteriosclerosis, and severe bilateral bronchopneumonia.

\section{REFERENCES}

1. Gamble, J. L., Companionship of Water and Electrolytes in the Organization of Body Fluids. Stanford, Calif., Stanford University Press, 1951.

2. Moore, F. D., Determination of total body water and solids with isotopes. Science, 1946, 104, 157.

3. Edelman, I. S., Olney, J. M., James, A. H., Brooks, L., and Moore, F. D., Body composition: Studies in the human being by the dilution principle. Science, 1952, 115, 447.

4. Edelman, I. S., James, A. H., Baden, H., and Moore, F. D., Electrolyte composition of bone and the penetration of radiosodium and deuterium oxide into dog and human bone. J. Clin. Invest., 1954, 33, 122.

5. Nichols, G., Jr., Nichols, N., Weil, W. B., and Wallace, W. M., The direct measurement of the extracellular phase of tissues. J. Clin. Invest., 1953, 32, 1299.

6. Nadell, J., Sweet, N. J., and Edelman, I. S., Gastrointestinal water and electrolytes. II. The equilibration of radiopotassium in gastrointestinal contents and the proportion of exchangeable potassium (K.) in the gastrointestinal tract. J. Clin. Invest., 1956, 35, 512 .

7. Sweet, N. J., Nadell, J., and Edelman, I. S., Gastrointestinal water and electrolytes. III. The equilibration of radiobromide in gastrointestinal contents and the proportion of exchangeable chloride $\left(\mathrm{Cl}_{0}\right)$ in the gastrointestinal tract. In preparation. 
8. Gotch, F., Nadell, J., and Edelman, I. S., Gastrointestinal water and electrolytes. IV. The equilibration of deuterium oxide in gastrointestinal contents and the proportion of total body water in the gastrointestinal tract. In preparation.

9. Visscher, M. B., Fetcher, E. S., Jr., Carr, C. W., Gregor, H. P., Bushey, M. S., and Barker, D. E., Isotopic tracer studies on the movement of water and ions between intestinal lumen and blood. Am. J. Physiol., 1944, 142, 550.

10. Cizek, L. J., Total water content of laboratory animals with special reference to volume of fluid within the lumen of the gastrointestinal tract. Am. J. Physiol., 1954, 179, 104.

11. Solomon, A. K., The half-life of sodium 24. Physical Rev., 1950, 79, 2d Ser., 403.

12. Edelman, I. S., James, A. H., Brooks, L., and Moore, F. D., Body sodium and potassium. IV. The normal total exchangeable sodium; its measurement and magnitude. Metabolism, 1954, 3, 530.

13. Moore, F. D., Edelman, I. S., Olney, J. M., James, A. H., Brooks, L., and Wilson, G. M., Body sodium and potassium. III. Interrelated trends in alimentary, renal and cardiovascular disease; lack of correlation between body stores and plasma concentration. Metabolism, 1954, 3, 334.

14. Lockwood, J. S., and Randall, H. T., The place of electrolyte studies in surgical patients. Bull. New York Acad. Med., 1949, 25, 228.

15. Carmichael, E. B., Strickland, J. T., and Driver, R. L., The contents of the stomach, small intestine, cecum and colon of normal and fasting rabbits. Am. J. Physiol., 1945, 143, 562.

16. Ingraham, R. C., and Visscher, M. B., Further studies on intestinal absorption with the performance of osmotic work. Am. J. Physiol., 1938, 121, 771.

17. Visscher, M. B., and Roepke, R. R., Osmotic and electrolyte concentration relationships during absorption of salt solutions from ileal segments. Am. J. Physiol., 1945, 144, 468.
18. Visscher, M. B., Varco, R. H., Carr, C. W., Dean, R. B., and Erickson, D., Sodium ion movement between the intestinal lumen and the blood. Am. J. Physiol., 1944, 141, 488.

19. Dennis, C., and Wood, E. H., Intestinal absorption in the adrenalectomized dog. Am. J. Physiol., 1940, 129, 182.

20. Woodbury, D. M., Extrarenal effects of desoxycorticosterone, adrenocortical extract and adrenocorticotrophic hormone on plasma and tissue electrolytes in fed and fasted rats. Am. J. Physiol., 1953, $174,1$.

21. Miller, H., and Wilson, G. M., The measurement of exchangeable sodium in man using the isotope $\mathrm{e}^{\mathrm{2t}} \mathrm{Na}$. Clin. Sc., 1953, 12, 97.

22. Forbes, G. B., and Perley, A., Estimation of total body sodium by isotopic dilution. I. Studies on young adults. J. Clin. Invest., 1951, 30, 558.

23. Montgomery, M. L., Sheline, G. E., and Chaikoff, I. L., Elimination of sodium in pancreatic juice as measured by radioactive sodium. Am. J. Physiol., 1941, $131,578$.

24. Kruhøffer, P., Inulin as an indicator for the extracellular space. Acta physiol. Scandinav., 1946, 11, 16.

25. Berger, E. Y., and Steele, J. M., Suppression of sodium excretion by the colon in congestive heart failure and cirrhosis of the liver demonstrated by the use of cation exchange resins. J. Clin. Invest., 1952, 31, 451.

26. Lavietes, P. H., Bourdillon, J., and Klinghoffer, $\mathrm{K}$. A., The volume of the extracellular fluids of the body. J. Clin. Invest., 1936, 15, 261.

27. Gregersen, M. I., and Wright, L., The effect of intravenous injection of sucrose and glucose upon the reducing power of cerebrospinal fluid, before and after hydrolysis. Am. J. Physiol., 1935, 112, 97.

28. Berger, E. Y., and Steele, J. M., Electrolyte and water metabolism: Physiologic considerations. M. Clin. North America, (May) 1952, 36, 829. 